\title{
The Impact of Post-Graduate Year of Primary Surgeon on Technical Performance Score in Tetralogy of Fallot Repair
}

\author{
Masatoshi Shimada, MD, PhD; Takaya Hoashi, MD, PhD; \\ Jun Iida, MD; Hajime Ichikawa, MD, PhD
}

\begin{abstract}
Background: The aim of this study was to assess the impact of surgeon years of experience on clinical outcomes of tetralogy of Fallot (TOF) repair using technical performance score (TPS), and to investigate the possibility of safe operations by surgical trainees.

Methods and Results: We assessed the cases of 159 consecutive patients who underwent TOF repair between 2001 and 2015. Thirteen different primary surgeons performed operations with 41 different first assistants. The primary surgeon and first assistant mean postgraduate years were 19.1 \pm 5.1 years (range, 5.7-31.6 years) and 11.2 \pm 6.3 years (range, 3.2-36.3 years), respectively. TPS was assigned using pre-discharge echocardiography based on original criteria. Logistic regression analysis was used to examine the factors associated with TPS. TPS could be scored for all patients, 16 of whom were graded as having optimal (10\%), 119 as adequate $(75 \%)$, and 24 as having inadequate (15\%) TPS. None of the preoperative and perioperative variables affected TPS. Although neither the primary surgeon nor the first assistant postgraduate years was associated with TPS independently, total primary surgeon and first assistant postgraduate years correlated with TPS (OR, 1.07; 95\% Cl: 1.01-1.13, $\mathrm{P}=0.031)$.
\end{abstract}

Conclusions: Primary surgeon postgraduate years was not associated with TPS for TOF repair. TOF repair can be performed adequately and safely by surgical trainees under the support of highly experienced supervisors.

Key Words: Surgical training; Technical performance score; Tetralogy of Fallot

$\mathrm{O}_{\mathrm{sca}} \mathrm{sen}$ urgical education for trainees in the field of congenital heart surgery is a crucial issue on a global scale. ${ }^{1}$ Whereas providing young surgeons with ample opportunities to perform technically demanding operations as a primary surgeon is essential for their education, even for complex procedures (e.g., congenital heart surgery) that involve multiple life-threating technical factors, recent investigations have demonstrated that patients treated by older surgeons had lower mortality rates than patients treated by younger surgeons. ${ }^{2}$ Although little has been reported on which individual and surgical team factors affect the clinical outcomes of complex congenital heart surgery, we hypothesized that surgical outcomes and procedure quality may also be improved when older surgeons perform the procedures.

Tetralogy of Fallot (TOF) repair is considered to be the first step in complex congenital cardiac surgery. Herein, this retrospective cohort assessed the correlation between surgeon years of experience either as primary surgeon or as a first assistant, and surgical performance in TOF repair using technical performance score (TPS). TPS was introduced as a useful tool in the evaluation of procedure quality. ${ }^{3}$ TPS is strongly associated with early- and inter- mediate-term clinical outcomes and can also serve as a predictor of need for reintervention regardless of patient age and disease complexity. ${ }^{4,5}$

\section{Methods \\ Patients and Surgical Procedure}

The National Cerebral and Cardiovascular Center Institutional Review Board approved this retrospective study, and opt-out consent was obtained instead of individual written informed consent (R19043-2). A total of 159 consecutive patients undergoing repair of TOF primarily or after systemic to pulmonary shunt between 2001 and 2015 were enrolled (Table 1). Patients with major aortopulmonary collateral arteries, atrioventricular septal defect, or absent pulmonary valve were excluded. Mean age and body weight at repair were $12.7 \pm 6.6$ months and $7.9 \pm 1.7 \mathrm{~kg}$, respectively. Nineteen patients $(11.9 \%)$ had pulmonary atresia, and 77 patients $(48.4 \%)$ had undergone palliative systemic to pulmonary shunt through lateral thoracotomy.

TOF repair was performed at between 2 months and 2 years of age following preoperative cardiac catheter evaluation. The patients with pulmonary atresia $(11.9 \%)$ under-

Received September 1, 2019; revised manuscript received December 2, 2019; accepted December 24, 2019; J-STAGE Advance Publication released online February 5, 2020 Time for primary review: 51 days

Department of Pediatric Cardiovascular Surgery, National Cerebral and Cardiovascular Center, Suita, Japan

Mailing address: Takaya Hoashi, MD, PhD, Department of Pediatric Cardiovascular Surgery, National Cerebral and Cardiovascular Center, 6-1 Kishibe-Shimmachi, Suita 564-8565, Japan. E-mail: thoashi@surg1.med.osaka-u.ac.jp

ISSN-1346-9843 All rights are reserved to the Japanese Circulation Society. For permissions, please e-mail: cj@j-circ.or.jp 


\begin{tabular}{lc|}
\hline Table 1. Patient Characteristics and Surgery Variables \\
Patient characteristics & \\
Age at repair (months) & $12.7 \pm 6.6(2.1-47)$ \\
Body weight at repair (kg) & $7.9 \pm 1.6(2.8-15)$ \\
Branch pulmonary stenosis & $43(27)$ \\
Discontinuous branch pulmonary arteries & $2(1.3)$ \\
Previous systemic-pulmonary shunt & $77(49)$ \\
Pulmonary atresia & $19(12)$ \\
Chromosomal anomalies & \\
$\quad$ Down syndrome & $11(6.9)$ \\
DiGeorge syndrome & $10(6.3)$ \\
Preoperative catheter examination & \\
LVEF (\%) & $67 \pm 6.4(47-84)$ \\
LVEDV (\% of normal) & $112 \pm 35(65-296)$ \\
Pulmonary valve diameter (\% of normal) & $76 \pm 17(31-124)$ \\
Pulmonary/systemic blood flow ratio & $1.6 \pm 0.8(0.36-4.7)$ \\
Operative variables & \\
Use of transannular patch & $110(69)$ \\
Operation time (min) & $346 \pm 93(205-779)$ \\
Cardiopulmonary bypass time (min) & $185 \pm 59(80-492)$ \\
Aortic cross-clamp time (min) & $90 \pm 34(39-288)$ \\
\hline
\end{tabular}

Data given as $\mathrm{n}(\%)$ or mean $\pm \mathrm{SD}$ (range). LVEDV, left ventricular end-diastolic volume; LVEF, left ventricular ejection fraction.

\begin{tabular}{|lc|}
\hline \multicolumn{2}{|l|}{ Table 2. Profiles of Primary Surgeon and First Assistant } \\
No. participating primary surgeons & 13 \\
No. participating first assistants & 41 \\
Surgeon experience (years) & \\
PGY-PS & $19.1 \pm 5.1(5.7-31.6)$ \\
PGY-A & $11.2 \pm 6.3(3.2-36.3)$ \\
PGY-Sr & $20.2 \pm 4.8(12.8-36.7)$ \\
PGY-PS+PGY-A & $30.4 \pm 6.8(16.6-56.5)$ \\
PGY-PS<PGY-A & $34(21.4)$ \\
\hline
\end{tabular}

Data given as mean \pm SD (range) or $n(\%)$. PGY, postgraduate years; PGY-A, postgraduate years of first assistant; PGY-PS, postgraduate years of primary surgeon; PGY-Sr, postgraduate years of supenvisor (the highest PGY surgeon on the surgical team).

went Rastelli type operation. In 110 patients (69.1\%), the right ventricular outflow tract (RVOT) was reconstructed using a transannular patch consisting of an expanded polytetrafluoroethylene patch with handmade expanded polytetrafluoroethylene monocusp. Mean pulmonary valve diameter measured on biplane cine-angiography was $76 \%$ of the normal predictive value. A transatrial/pulmonary approach was used for the remaining patients (19.0\%).

\section{Surgical Team Profile}

The surgical team consisted of 3 surgeons: the primary surgeon; first assistant; and second assistant. Profiles of the primary surgeon and first assistant who participated in these operations are summarized in Table 2. Thirteen different primary surgeons performed TOF repair, with 41 different first assistants. As an explanatory variable representing the degree of surgeon maturity or experience, postgraduate years (PGY) was used instead of age. PGY was defined as years after graduation from medical school (including the time spent as a resident). Mean primary

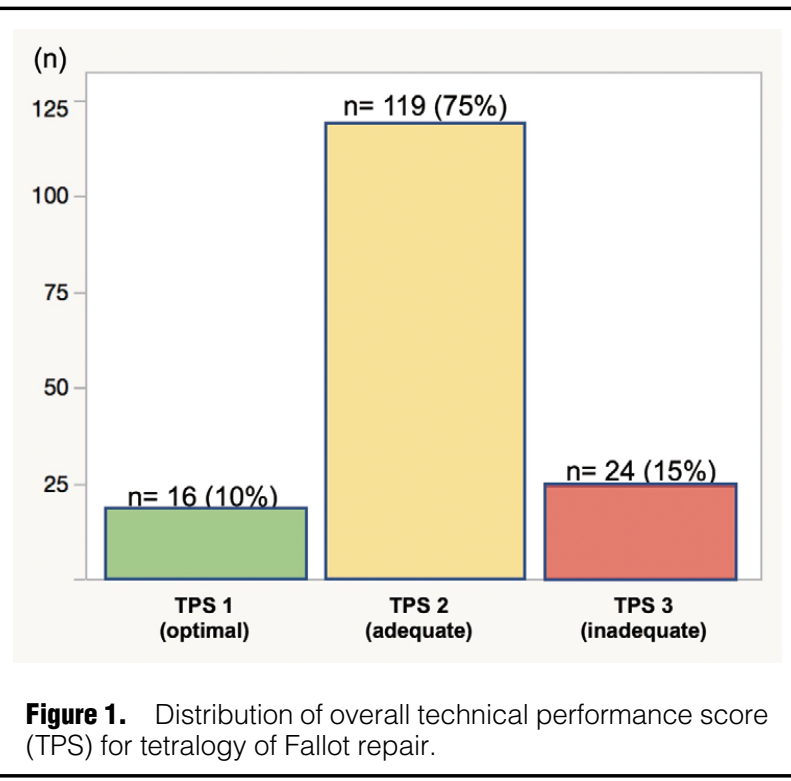

surgeon postgraduate years (PGY-PS) and first assistant postgraduate years (PGY-A) were 19.1 \pm 5.1 years (range, 5.7-31.6 years) and $11.2 \pm 6.3$ years (range, $3.2-36.3$ years), respectively. Mean total PGY-PS+PGY-A was $30.4 \pm 6.8$ years (range, 16.6-56.5 years). Mean PGY of the supervisor (PGY-Sr), the senior surgeon with the highest PGY on the surgical team, was 20.2 \pm 4.8 years (range, 12.8-36.7 years). The supervisor also participated in the operation as a first assistant. The number of cases in which the primary surgeon had a lower PGY than the assistant (PGY-PS $<$ PGY-A) was $34(21.4 \%)$.

\section{TPS}

With reference to a published scoring tool, ${ }^{3}$ TPS was assigned according to the pre-discharge 2-D and color Doppler echocardiogram and clinical status. The TOF repair surgical procedure was divided into subprocedures: atrial septal defect repair; ventricular septal defect repair (conoventricular and muscular); RVOT repair; pulmonary valve intervention; pulmonary artery plasty (main trunk, right pulmonary artery, and left pulmonary artery); and patent ductus arteriosus closure. Each subprocedure was categorized as optimal, adequate, or inadequate using specific echocardiography criteria. In addition, prevention of conduction injury throughout the entire procedure was also evaluated. Finally, TPS was defined as: optimal if all subprocedures were graded as optimal (TPS 1, no residual defect); adequate if at least 1 subprocedure was graded as adequate and there were no inadequate scores (TPS 2 , minor residual); and inadequate if any subprocedure was graded as inadequate (TPS 3, major residual). Unplanned surgical or catheter reintervention in the anatomic area treated during the operation resulted in an inadequate TPS.

\section{Statistical Analysis}

This was a retrospective, non-randomized, single-center study. Once the TPS had been determined in all study cohorts, the impact of TPS on in-hospital outcomes, and the association of pre- and perioperative variables, including surgeon experience with TPS, were examined. Continuous 


\begin{tabular}{lccc|}
\hline \multicolumn{1}{c|}{ Table 3. Subprocedure Scores in TPS 3 Patients $(\mathbf{n = 2 4 )}$} & & Adequate & Inadequate \\
Strial septal defect repair & Optimal & $0(0)$ & $0(0)$ \\
Ventricular septal defect repair & $24(100)$ & $6(25)$ & $7(29)$ \\
Relief of RVOT obstruction & $11(46)$ & $1(4)$ & $11(46)$ \\
Pulmonary valve reconstruction & $12(50)$ & $7(29)$ & $1(4)$ \\
Reconstruction of main PA & $16(67)$ & $0(0)$ & $4(17)$ \\
Reconstruction of right PA & $20(83)$ & $0(0)$ & $0(0)$ \\
Reconstruction of left PA & $24(100)$ & $1(4)$ & $2(8)$ \\
PDA closure & $21(88)$ & $0(0)$ & $0(0)$ \\
Conduction & $24(100)$ & $0(0)$ & $0(0)$ \\
\hline
\end{tabular}

Data given as $n$ (\%). PA, pulmonary artery; PDA, patent ductus arteriosus; RVOT, right ventricular outflow tract; TPS, technical performance score.

\begin{tabular}{|c|c|c|c|c|c|c|}
\hline & \multicolumn{4}{|c|}{ TPS } & \multirow{2}{*}{\multicolumn{2}{|c|}{$\begin{array}{c}\text { Inadequate TPS } \\
\text { Univariate }\end{array}$}} \\
\hline & \multicolumn{2}{|c|}{ Univariate } & \multicolumn{2}{|c|}{ Multivariate } & & \\
\hline & OR $(95 \% \mathrm{Cl})$ & P-value & OR $(95 \% \mathrm{Cl})$ & P-value & OR $(95 \% \mathrm{Cl})$ & P-value \\
\hline Age at repair & $1.14(0.96-1.94)$ & 0.605 & & & $0.93(0.85-1.01)$ & 0.079 \\
\hline Body weight at repair & $1.15(0.91-1.47)$ & 0.239 & & & $0.85(0.62-1.16)$ & 0.291 \\
\hline Discontinuous branch PA & $0.32(0.06-1.42)$ & 0.124 & $0.49(0.09-2.22)$ & 0.342 & $1.04(0.08-3.71)$ & $>0.99$ \\
\hline Previous systemic-pulmonary shunt & $0.90(0.62-1.28)$ & 0.551 & & & $1.14(0.48-2.74)$ & 0.757 \\
\hline Pulmonary atresia & $1.28(0.76-2.14)$ & 0.351 & & & $0.95(0.25-3.54)$ & 0.938 \\
\hline \multicolumn{7}{|l|}{ Chromosomal anomalies } \\
\hline Down syndrome & $0.71(0.37-1.41)$ & 0.333 & & & $4.52(0.56-588)$ & 0.094 \\
\hline DiGeorge syndrome & $0.88(0.44-1.74)$ & 0.723 & & & $4.10(0.50-534)$ & 0.117 \\
\hline \multicolumn{7}{|l|}{ Preoperative catheter examination } \\
\hline LVEF & $1.46(0.98-1.10)$ & 0.197 & $1.04(0.98-1.10)$ & 0.192 & $0.29(0.02-3.76)$ & 0.341 \\
\hline LVEDV & $0.99(0.99-1.01)$ & 0.416 & & & $1.00(0.99-1.01)$ & 0.644 \\
\hline Pulmonary valve diameter & $1.00(0.98-1.03)$ & 0.902 & & & $0.83(0.05-12.7)$ & 0.893 \\
\hline Pulmonary/systemic blood flow ratio & $0.97(0.50-1.32)$ & 0.397 & & & $1.94(0.17-22.5)$ & 0.604 \\
\hline Transannular patch & $1.18(0.80-1.76)$ & 0.803 & & & $1.37(0.71-3.70)$ & 0.528 \\
\hline Cardiopulmonary bypass time & $0.99(0.98-1.00)$ & 0.272 & & & $1.01(1.00-1.01)$ & 0.165 \\
\hline Aortic cross-clamp time & $0.99(0.99-1.01)$ & 0.356 & & & $1.01(1.00-1.03)$ & 0.078 \\
\hline PGY-PS & $1.02(0.99-1.09)$ & 0.603 & & & $0.99(0.90-1.07)$ & 0.745 \\
\hline PGY-A & $1.06(0.99-1.12)$ & 0.052 & & & $0.94(0.87-1.02)$ & 0.143 \\
\hline PGY-Sr & $1.06(0.98-1.14)$ & 0.126 & & & $0.93(0.84-1.03)$ & 0.170 \\
\hline PGY-PS+PGY-A & $1.06(1.01-1.12)$ & 0.030 & $1.07(1.01-1.13)$ & 0.031 & $0.95(0.88-1.02)$ & 0.123 \\
\hline PGY-PS < PGY-A & $1.26(0.82-1.97)$ & 0.289 & & & $0.48(0.13-1.71)$ & 0.225 \\
\hline
\end{tabular}

Abbreviations as in Tables 1-3.

variables are expressed as mean $\pm \mathrm{SD}$ or median (range), and categorical variables are presented as n $(\%)$. Factors associated with TPS (as an ordinal variable) and inadequate TPS were analyzed on ordered logistic regression analysis and nominal logistic regression analysis, respectively, with odds ratios and 95\% CI. Data were analyzed using JMP Pro 14 (SAS Institute, Cary, NC, USA), and the differences were considered statistically significant at $\mathrm{P}<0.05$.

\section{Results}

\section{Overall TPS}

TPS could be assigned for all patients. TPS was categorized as optimal (TPS 1 ) for 16 patients (10\%), adequate (TPS 2 ) for 119 patients (65\%), and inadequate (TPS 3) for 24 patients $(25 \%$; Figure 1). Subprocedure scoring in the case of inadequate TPS (TPS 3) is given in Table 3. The most frequent inadequate subprocedure was relief of RVOT obstruction $(11 / 24,46 \%)$, followed by ventricular septal defect repair $(7 / 24,29 \%)$ and reconstruction of main pulmonary artery $(4 / 24,17 \%)$. No patients had complications with surgical heart block in this series. Re-do surgical intervention before discharge was performed on 4 patients: RVOT reconstruction for 2 , patch augmentation of bilateral branch pulmonary arteries for 1 , and one and one-half repair for 1 . No patient required catheter re-intervention before discharge.

\section{In-Hospital Outcomes}

Four patients required perioperative extracorporeal membrane oxygenation (ECMO) support; weaning from ECMO was accomplished for 2 of them following re-do 


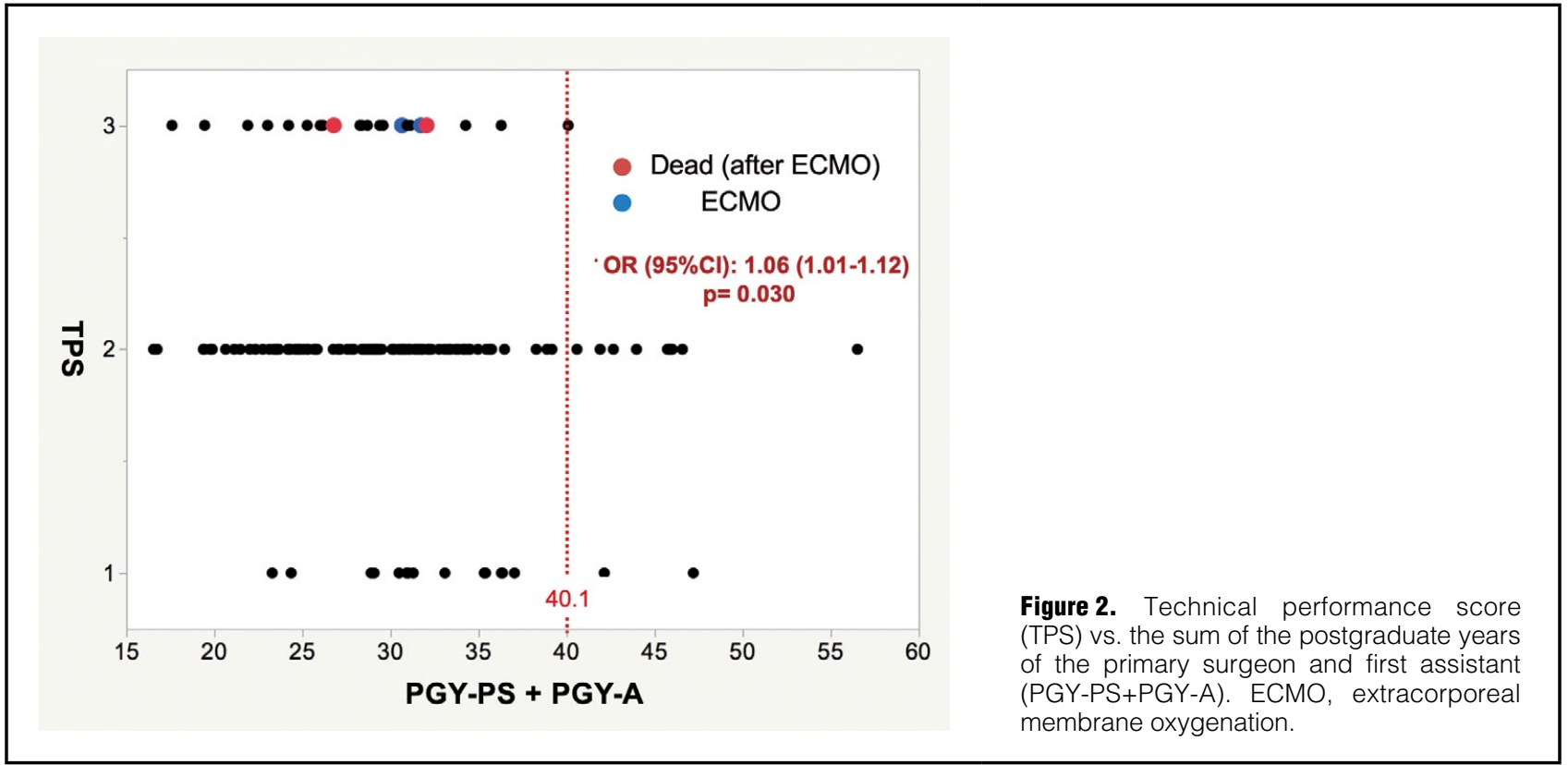

surgical intervention soon after the initial operation. The third patient developed severe hypoxia after the operation and required ECMO support. ECMO could not be disconnected after the improvement of the lung condition, and subsequent examination indicated a small tricuspid valve and right ventricular cavity. That patient underwent one and one-half ventricular conversion and was successfully weaned off ECMO. The fourth patient required patch augmentation of bilateral branch pulmonary arteries for peripheral pulmonary stenosis, resulting in unsuccessful weaning from cardiopulmonary bypass even after removal of ventricular septal defect patch. There were 2 in-hospital deaths before weaning from ECMO. In both cases the patients required intraoperative initiation of ECMO due to severe heart failure. Although coronary arteries such as left main trunk, left anterior descending, or septal perforator were suspected as having been injured at RVOT reconstruction, low cardiac output continued even after the revision of RVOT reconstruction.

\section{TPS and Risk Analysis}

On univariate analysis and multivariate ordered logistic regression analysis, only total PGY-PS+PGY-A correlated with TPS (OR, 1.07; 95\% CI: 1.01-1.13; P=0.031; Table 4). In contrast, no variables related to PGY, including total PGY-PS+PGY-A, were identified as predictors of inadequate TPS. Pre- and perioperative variables were not associated with TPS or inadequate TPS.

The correlation between total PGY-PS+PGY-A and TPS is shown in Figure 2. The highest total PGY-PS+PGY-A in the inadequate TPS group was 40.1 years; that is, no operation received an inadequate TPS with a total PGYPS+PGY-A above 40.1 years. All deaths and requirement for perioperative ECMO occurred in the inadequate TPS group, and the total PGY-PS+PGY-A in those specific cases was $<32.1$ years.

\section{Discussion}

Several studies have reported on the impact of human factors such as surgeon age or other surgeon characteristics on outcomes in adult cardiac surgery. ${ }^{6-9}$ The influence of the surgical training system, the hospital, and individual surgical volume has also been discussed. ${ }^{10-13}$ Little, however, has been reported on congenital cardiac surgery. ${ }^{14}$ This study is the first to investigate the impact of human factors on the outcomes of congenital cardiac surgery using TPS. Inadequate TPS has been reported to be associated with in-hospital outcomes., ${ }^{\mathbf{4 5}, 15-21}$ TPS could therefore be considered a reasonable tool and indicator of surgery quality.

The primary finding of this study was that neither lower PGY-PS nor lower PGY-A was correlated with TPS individually, but that total PGY-PS+PGY-A was. This could be interpreted to indicate that surgical trainees with lower PGY could perform TOF repair without worsening TPS. Concerning the association between total PGY-PS+ PGY-A and TPS, it is possible that the supervisory first assistant could have a complementary and supportive impact on the procedure for maintaining trainee quality. It follows that TOF repair can be performed adequately and safely by trainees with the support of highly experienced supervisors. Although the correlation between total PGYPS+PGY-A and inadequate TPS was not statistically significant, which could be due to the fact that there were few cases of inadequate TPS in this cohort, it would be preferable to make total PGY-PS+PGY-A as high as possible to offer better procedural safety and quality. In the present series, both deaths that occurred after ECMO initiation, happened in cases of total PGY-PS+PGY-A $<20.4$ years, and both of the cases in which the patients were successfully weaned from perioperative ECMO after an additional operation had a total PGY-PS+PGY-A $>24.4$ years. When facing critical problems, in addition to total PGY-PS+PGY-A, an experienced supervisor with a relatively high PGY may hold the key to the solution for the crisis. 
Second, the fact that the study focused on a single procedure may have prevented PGY from having a negative effect on outcome. Under ordinary circumstances, an inexperienced surgeon would be put in charge of relatively simple cases, while a senior or experienced surgeon would tend to be assigned to complicated cases involving higher levels of difficulty. This may be one of the reasons why several studies have reported that worsening patient outcomes or complication rates increase with surgeon age. ${ }^{22,23}$ As noted in the literature, ${ }^{2}$ it seems that the impact of human factors on surgical outcomes becomes less prominent as illness severity or surgical difficulty decrease.

Surgical quality is not decided only by the sum of subprocedure performance quality. The cannulation for the establishment of cardiopulmonary bypass, dissection around the heart and vessels, hemostasis before chest closure, and so on are very important technical aspects of the safety of complex congenital heart surgery. In contrast, the life-threating technical complications of TOF repair consist of aortic valve injury, coronary injury, or septal perforation as a result of inadequate relief of RVOT obstruction and closure of ventricular septal defect. A residual pressure gradient $>40 \mathrm{mmHg}$ at the branch pulmonary artery is a serious problem that sometimes results in unsuccessful weaning off cardiopulmonary bypass and in subsequent adverse events. Not only the supervisor and trainee, but also all members of the surgical team should keep in mind that there are numerous procedural factors that can cause serious complications.

\section{Study Limitations}

Being a retrospective, single-center study, this study has several limitations. First, general assumptions should not be extrapolated from the results of such a small cohort.

Second, the echocardiography studies used in generating TPS were not reported by the same examiner, but were determined through an operator-dependent technique. TPS has been developed in the health and medical environment specific to the USA, and it is not clear whether this scoring system functions in a similar manner in other countries.

Finally, the same trends of association between surgeon experience and TPS are not necessarily recognized in other procedures with varying levels of difficulty. Whereas surgical outcomes of the repair of simple congenital heart defects may not depend on surgeon experience, outcomes of more technically demanding surgeries such as neonatal arterial switch, Norwood, or surgery for heterotaxy syndrome would be independently affected by surgeon performance. The combined abilities of the surgical team may be emphasized for TOF repair because TOF repair is relatively frequent, elective, and is a mildly difficult procedure with various surgical options (with or without native pulmonary valve, with or without right ventriculotomy, or need for reconstruction of blanch pulmonary artery) in patients with stable hemodynamic conditions.

\section{Conclusion}

Surgeon years of experience was not associated with TPS for TOF repair, but the sum of the primary surgeon and first assistant years of experience had a positive correlation with TPS. TOF repair can be performed adequately and safely by surgical trainees with the support of a highly experienced supervisor.
Acknowledgments / Funding Statement / Disclosures None.

\section{Conflict of Interest}

None declared.

\section{References}

1. Ohye RG, Jaggers JJ, Sade RM. Must surgeons in training programs allow residents to operate on their patients to satisfy board requirements? Ann Thorac Surg 2016; 101: 18-23.

2. Tsugawa Y, Jena AB, Orav EJ, Blumenthal DM, Tsai TC, Mehtsun WT, et al. Age and sex of surgeons and mortality of older surgical patients: Observational study. BMJ 2018; 361: $\mathrm{k} 1343$.

3. Larrazabal LA, del Nido PJ, Jenkins KJ, Gauvreau K, Lacro R, Colan SD, et al. Measurement of technical performance in congenital heart surgery: A pilot study. Ann Thorac Surg 2007; 83: $179-184$.

4. Nathan M, Marshall AC, Kerstein J, Liu H, Fynn-Thompson F, Baird CW, et al. Technical performance score as predictor for post-discharge reintervention in valve-sparing tetralogy of Fallot repair. Semin Thorac Cardiovasc Surg 2014; 26: 297-303.

5. Cunningham MEA, Donofrio MT, Peer SM, Zurakowski D, Jonas R, Sinha P. Influence of age and weight on technical repair of tetralogy of Fallot. Ann Thorac Surg 2016; 102: 864-869.

6. Haan CK, Milford-Beland S, O'Brien S, Mark D, Dullum M, Ferguson TB, et al. Impact of residency status on perfusion times and outcomes for coronary artery bypass graft surgery. Ann Thorac Surg 2007; 83: 2103-2110.

7. Bakaeen FG, Dhaliwal AS, Chu D, Bozkurt B, Tsai P, LeMaire SA, et al. Does the level of experience of residents affect outcomes of coronary artery bypass surgery? Ann Thorac Surg 2009; 87: $1124-1127$

8. Dewey TM, Herbert MA, Ryan WH, Brinkman WT, Smith R, Prince SL, et al. Influence of surgeon volume on outcomes with aortic valve replacement. Ann Thorac Surg 2012; 93: 1103-1107.

9. Burt BM, ElBardissi AW, Huckman RS, Cohn LH, Cevasco MW, Rawn JD, et al. Influence of experience and the surgical learning curve on long-term patient outcomes in cardiac surgery. J Thorac Cardiovasc Surg 2015; 150: 1061-1067.

10. Gopaldas RR, Bakaeen FG, Dao TK, Coselli JS, LeMaire SA, Huh J, et al. Outcomes of concomitant aortic valve replacement and coronary artery bypass grafting at teaching hospitals versus nonteaching hospitals. J Thorac Cardiovasc Surg 2012; 143: 648-655.

11. Dewey TM, Herbert MA, Ryan WH, Brinkman WT, Smith R, Prince SL, et al. Influence of surgeon volume on outcomes with aortic valve replacement. Ann Thorac Surg 2012; 93: 1103-1107.

12. Khera R, Pandey A, Koshy T, Ayers C, Nallamothu BK, Das $\mathrm{SR}$, et al. Role of hospital volumes in identifying low-performing and high-performing aortic and mitral valve surgical centers in the United States. JAMA Cardiol 2017; 2: 1322-1331.

13. Norcini JJ, Boulet JR, Opalek A, Dauphinee WD. Outcomes of cardiac surgery: Associations with physician characteristics, institutional characteristics, and transfers of care. Med Care 2013; 51: 1034-1039.

14. de Leval MR, Carthey J, Wright DJ, Farewell VT, Reason JT. Human factors and cardiac surgery: A multicenter study. J Thorac Cardiovasc Surg 2000; 119: 661-672.

15. Bacha EA, Larrazabal LA, Pigula FA, Gauvreau K, Jenkins KJ, Colan SD, et al. Measurement of technical performance in surgery for congenital heart disease: The stage I Norwood procedure. J Thorac Cardiovasc Surg 2008; 136: 993-997.

16. Karamichalis JM, Thiagarajan RR, Liu H, Mamic P, Gauvreau K, Bacha EA. Stage I Norwood: Optimal technical performance improves outcomes irrespective of preoperative physiologic status or case complexity. J Thorac Cardiovasc Surg 2010; 139: 962-968.

17. Nathan M, Karamichalis JM, Liu H, del Nido P, Pigula F, Thiagarajan $R$, et al. Intraoperative adverse events can be compensated by technical performance in neonates and infants after cardiac surgery: A prospective study. $J$ Thorac Cardiovasc Surg 2011; 142: $1098-1107$.

18. Nathan M, Karamichalis JM, Liu H, Emani S, Baird C, Pigula $\mathrm{F}$, et al. Surgical technical performance scores are predictors of late mortality and unplanned reinterventions in infants after cardiac surgery. J Thorac Cardiovasc Surg 2012; 144: 1095-1101. 
19. Nathan M, Pigula FA, Liu H, Gauvreau K, Colan SD, FynnThompson F, et al. Inadequate technical performance scores are associated with late mortality and late reintervention. Ann Thorac Surg 2013; 96: 664-669.

20. Nathan M, Karamichalis J, Liu H, Gauvreau K, Colan S, Saia $\mathrm{M}$, et al. Technical performance scores are strongly associated with early mortality, postoperative adverse events, and intensive care unit length of stay: Analysis of consecutive discharges for 2 years. J Thorac Cardiovasc Surg 2014; 147: 389-394.

21. Tishler B, Gauvreau K, Colan SD, del Nido P, Nathan M.
Technical performance score predicts partial/transitional atrioventricular septal defect outcomes. Ann Thorac Surg 2018; 105: $1461-1468$.

22. Duclos A, Peix JL, Colin C, Kraimps JL, Menegaux F, Pattou $\mathrm{F}$, et al. Influence of experience on performance of individual surgeons in thyroid surgery: Prospective cross sectional multicentre study. BMJ 2012; 344: d8041.

23. Waljee JF, Greenfield LJ, Dimick JB, Birkmeyer JD. Surgeon age and operative mortality in the United States. Ann Surg 2006; 244: $353-362$. 